\title{
Illocutional concurrences: The case of evaluative speech acts and face-work in spoken Mandarin and American English
}

\begin{abstract}
This paper proposes a novel usage-based approach to modal and illocutionary analysis. As a case study, it provides a holistic picture of the interplay between evaluations and face-work (i.a. Goffman 1967) as they occur in the Spoken Callhome corpora of Mandarin and American English. We plotted a conditional inference tree model (Hothorn et al. 2006) to gather what we call languagespecific illocutional concurrences (IC). IC encompass converging factors at various levels of verbal experience that contribute both locally (i.e. at the morphosyntactic level) and peripherally (i.e. at the illocutionary level) to the encoding of contextually and culturally situated speech acts or pragmemes (i.a. Mey 2001; Author 2016a). From this study will emerge that Mandarin evaluations tend to include a higher number of instances of propositional face-work, viz. cases where the speaker overtly addresses the hearer as the target of his/her evaluation. Similarly, Mandarin evaluations show higher illocutional complexity, in the sense of having a more diverse pool of overtly coded dimensions that speakers account for whilst making evaluations. Finally, Mandarin evaluations also show a stronger tendency to overtly account for harmonious rapport-maintenance (i.a. Goffman 1967; Spencer-Oatey 2008) and intersubjectivity (i.a. Traugott \& Dasher 2002; Traugott 2010).
\end{abstract}

\section{Introduction}

This study aims at disentangling the role played by pragmatic, syntactical and semantic factors in the encoding of modal evaluations in Mandarin and American English (henceforth AE). The present analysis will unveil that modalised evaluative speech acts in the two languages show remarkable mismatches underpinning face, the presence of sentence-periphery and intersubjective marking. In fact, Chinese evaluations will show a much stronger tendency to overtly account for the addressee's potential reactions to the utterance. Similarly, they will unveil a higher proportion of cases where the addressee is the target of the speakers' evaluations. 
This novel usage-based approach to modal and illocutionary analysis aims at providing a holistic picture of evaluations as they occur cross-linguistically and cross-culturally. The ultimate goal of this paper is to develop a corpus-based paradigm centred on the utterance of a unit of meaning, informing typological and cross-cultural pragmatic research on modality, but also significantly impacting research on intercultural communication. We plotted a conditional inference tree model (Hothorn et al. 2006; Tagliamonte \& Bayen 2012) to gather unbiased converges of form, meaning, contextual conditions and pragmatic effects that contribute to the spontaneous encoding of evaluations in the two languages. Significant intersections of any of the variables subsumed by any of these 4 dimensions is what we call illocutional concurrences (IC). IC encompass converging factors at various levels of verbal experience that contribute both locally (i.e. at the morphosyntactic level) and peripherally (i.e. at the illocutionary level) to the encoding of contextually and culturally situated speech acts or pragmemes (i.a. Mey 2001; Capone 2005; Author 2016a).

We gathered our data from two comparable spoken corpora of spontaneous telephone conversation, respectively the CallHome corpus of Mandarin and $\mathrm{AE}^{1}$. Our results are further substantiated by additional methods of data-manipulation such as random forest modelling (i.a. Breiman 2001) and multiple correspondence analysis (Nenadic \& Greenacre 2007). Mandarin evaluations will show a tendency to include a significantly higher number of instances of propositional face-work, viz. cases where the speaker (henceforth, S) overtly addresses the hearer (henceforth, H) as the target of his/her evaluation. Similarly, our Mandarin dataset is characterised by a significantly higher illocutional complexity, in the sense of having a much more diverse range of overtly coded dimensions that speakers account for whilst making evaluations. Finally, Mandarin evaluations will also show a stronger tendency to overtly account for face-work management (i.a. Goffman 1967) and intersubjectivity (i.a. Traugott \& Dasher 2002; Traugott 2010).

A fundamental prerequisite for carrying out a large-scale corpus-based analysis encompassing formal and functional variables is probably the identification of the annotation criteria both theoretically and operationally. To do so, sections 1 and 2 aim at narrowing down the scope of our survey both theoretically and methodologically. More specifically, in section 1.1 we first introduce the notion of evaluations and how they intersect with a number of modal categories. In section 2 we discuss the notion of 'face-work' (i.a. Goffman 1961, 1967) in connection with evaluations. Section 2.1 then provides a multilayered taxonomy, addressing face-work as a dimension that is primarily driven by interactants' intentions to enhance, neglect, challenge or

\footnotetext{
1 https://talkbank.org/access/CABank/CallHome/zho.html; https://talkbank.org/access/CABank/CallHome/eng.html (Last accessed 7/04/18).
} 
maintain their on-going rapport (cf. Spencer-Oatey 2008). The rest of section 2 focuses on the interactional relationship between rapport-management and clause-peripheral pragmatic marking (PMs) in American English and Mandarin evaluative speech acts. Section 3 illustrates the retrieval of our data and the operationalization of our annotation criteria. Section 4 introduces the important notions of propositional face-work and illocutional concurrence and puts them into practise through language-specific conditional inference tree modelling, random forest and multiple correspondence analysis. In section 5 are formulated the conclusions of this study.

\subsection{Modalised evaluations}

In Searlean terms, evaluations might be considered a subclass either of assertions (evaluations involve an affirmation of some proposition) or of expressives (they imply the expression of a certain psychic state). Along a similar line of thought, Lyons (1977) refers to connotations, Hallyday (1994) generally defines the same class of speech acts as attitudes, while the notion of stance or appraisals are adopted in Martin \& White (2005) Conrad \& Biber (2000), Englebretson (2007). In Dam-Jensen \& Zethsen (2007) evaluations are intended to regard communal value systems and relations between language and society. In their view, 'evaluations' regard positive/ negative interpretations of linguistic expressions and the context in which they occur. Hunston \& Thompson (2000) look at evaluations as the speaker's (S) linguistic act of expressing his/her opinion, which may either qualify a proposition as (un-)certain or evaluate a state-of-affairs as positive vs negative. Their working definition of evaluations acknowledges a clear overlap with modality, while stressing the "speaker or writer's attitude or stance towards, view point on, or feelings about the entities or the propositions that he or she is talking about. That attitude may relate to certainty or obligation or desirability or any of a number of other sets of values" (2000: 5).

This study is centred on modalised evaluations (i.a. Papafragou 2000; Palmer 2001; Narrog 2005a, 2005b, 2012), viz. evaluative speech acts that distinctively include a modal item qualifying the proposition in terms of certainty, obligations, wants and so on. Importantly, evaluative speech acts do often intersect with modal elements which can be performative (involving the speaker's own, subjective evaluation) or descriptive (reporting the epistemic qualification of a state of affair) (i.a. Author 2017c; Aijmer 2018; Nuyts 2018). In fact, most modal subtypes often count as attitudinal categories, viz. involving the extent to which the assessor can commit him/herself to the state of affairs (i.a. Lyons 1977; Palmer 1986; Bybee et al. 1994; Narrog 2005a, 2005b, 2018). This approach covers deontic modality (the extent of the assessor's moral commitment) and epistemic 
modality (the extent of the assessor's existential commitment). However, still according to Nuyts (2005; 2018), it may exclude "dynamic modality (including situational modality: when a speaker states that it can rain here in summer, i.e. that there is a potential for rain, (s)he is describing facts, but not expressing a degree of commitment to the state of affairs)" (Nuyts 2018: 44).

Concerning this issue, it is important to note that the categorisation of evaluative speech acts in the present study adopts a sensibly broader stance, thus including both performative and descriptive usages of modalised expressions, as long as they contribute to the encoding of some evaluative force. In this sense, even dynamic-situational modality, as descriptive as it may be, can underpin the pragmatic attempt of evaluating the state of affairs of some situation or event. In (1) below, can encodes situational modality while still conveying a certain degree of evaluative force, as the rebuking of the reasoning process behind the utterance is not consistent with what said previously (cf. Author 2016a on evaluational distancing):

(1) Help can be summoned from ACET or other services merely by pressing a button on a pendant worn around the neck.

BNC A00 284

(1) a. *Help can be summoned from ACET or other services merely by pressing a button on a pendant worn around the neck, although I don't think so.

It is also worth considering that illocutionary forces are not independent or disassociated and rather tend to overlap within the same utterance (cf. Searle \& Vanderveken 1985). This crucially entails that even speech acts that are often associated with specific modal meanings are themselves paired with merging illocutionary forces, which, in turn, also contribute to the encoding of S' co-actions and intentions. For instance this is often the case of deontic modals, bringing together both directive and evaluative forces, thus still not allowing evaluational distancing (cf. Author 2016a):

(2) And now, please, you must go.

BNC C8A 1921

(2) a. *And now, please, you must go, but I don't think so.

While (2) undoubtedly expresses a directive meaning, it also intersects with a speech act of evaluation, which inherently prevents $\mathrm{S}$ from taking a distance from the reasoning process behind $\mathrm{p}$ in $(2 a)$. 
This paper presents a corpus-based enquiry of modalised utterances that are characterised by different degrees of evaluative force $(\operatorname{Ev} F(\mathrm{p}))$, i.e. where the direction of fit is "words to the world" with S expressing either overt or assumed "psychological state of Belief that (p): $\dashv \downarrow B(p)$ " (cf. Searle 1979: 12). This is included in the pool of speech acts where we will try to assess the intersubjective role played by face-work in interaction, i.e. impinging on S's intention to overtly account for H's persona and potential reactions to his/her evaluations.

\section{The evaluative nature of face}

Modality is traditionally associated with the semantic qualification of a proposition, underpinning a speaker's general intentions and commitment to how believable, obligatory, desirable, or actual a proposition is (i.a. Palmer 2001). Over the last decades modality has been increasingly discussed with respect to "interactional, textual and rhetorical functions, such as persuading, manipulating, challenging, confronting, accepting, encouraging the flow of the conversation and creating cohesive texts" (cf. Cornillie \& Pietrandrea 2012: 2109; i.a. see also Simon-Vanbergen \& Aijmer 2007; Englebreston 2007; Author 2016a, 2017a). Despite such pragmatic turn of modal enquiry, the role played by face in connection with modal qualification has been surprisingly neglected.

The notion of face is first introduced in academic research by Goffman $(1961,1967)$ who describes it as the foundation of the organisation of interpersonal encounters, and elevates it to "the traffic rules of social interaction" (1967:12). In pragmatics, this concept directly informs Brown \& Levinson's research on (im-)politeness (1987). However, while Brown \& Levinson address face as a personal possession, Goffman $(1961,1967)$ gives more emphasis to its evaluative nature, with a special focus on evaluations made by others. Brown and Levinson's (1987) influential conceptualization of face has been challenged for neglecting the interpersonal or social perspective on face, while over-empasizing the Western ideal of individual freedom and autonomy. Matsumoto (1988), Ide (1989) and Mao (1994) all stress the importance of "social identity" as a concept in Japanese and Chinese societies. Mao (1994) in particular proposes that two competing forces shape our interactional behaviour: the ideal of social identity and the one of individual autonomy. Similarly, Gao (2009:183) regards 'giving face' as one of the most practiced skills in Chinese social interaction, and she maintains that through giving face, "others' personal and social identities are maintained, affirmed, and/or promoted".

\subsection{Face within and beyond interaction}


The accent often placed on the culture-specific dimension of face often intersects with a more general concern for identity during and beyond interaction (i.a. Spencer-Oatey \& Ruhi 2007). Concerning this issue Haugh \& Bargiela-Chiappini (2010: 2073) raise the question of whether research on face can be "distinguished in any meaningful way from broader work on identity" (ibid.; see also Haugh 2009: 3). Indeed, in a number of accounts identity is seen as a byproduct of interaction (Heritage 2001: 48; Hecht et al. 2005; Benwell \& Stokoe 2006), while in other cases it has been described as a dimension enduring across interactions unless otherwise challenged (Spencer-Oatey, 2005:102-103).

This study addresses face from a usage-based angle, thus endorsing a relatively recent move in pragmatics "towards examining samples of real-life interaction" consistently with "a conceptualisation of face as interactional in this ordinary sense" (Haugh \& Bargiela-Chiappini 2010: 2074). This new turn, is informed by the so-called 'co-constituting model of communication' (Arundale 2010), which focuses on the relationship that is achieved interactionally between two or more persons, rather than a person-centred construct such as Goffman's (1955) claimed self-image/social identity, or Brown and Levinson's (1987) social wants.

In light of this, our study provides a corpus-based account centred on the interactional management of face. This approach has some downsides, as it cannot fully capture the long-term construing of personas' face and their perception within a social group from an ethnomethodological perspective (i.a. Samra \& Fredericks 2010). On the other hand, corpus-based analysis has the advantage of capturing face-work when it occurs as an overtly codified phenomenon, shedding light on large-scale 'overt' signs of face-management. In addition, when addressed operationally as an overtly marked device, face-work that can be statistically analysed and compared cross-linguistically and cross-culturally.

\subsection{Face as a multifaceted rapport-oriented dimension}

Brown \& Levinson (1987) distinctively focus on how people rationally 'calculate' the weightiness of a face threatening acts (FTA) and choose a strategy corresponding to the perceived level of face threat. In their framework there is a clear stress on face-threatening potential of any speech act. A broader perspective is taken by Spencer-Oatey (2008), who proposes that people can hold four different types of rapport orientation: 
1. Rapport enhancement orientation: a desire to strengthen or enhance harmonious relations between the interlocutors.

2. Rapport maintenance orientation: a desire to maintain or protect harmonious relations between the interlocutors.

3. Rapport neglect orientation: a lack of concern or interest in the quality of relations between the interlocutors (perhaps because of a focus on self).

4. Rapport challenge orientation: a desire to challenge or impair harmonious relations between the interlocutors.

(Spencer-Oatey, 2008:32)

While most of research on face and (im-)politeness is often centred on the evaluative nature of (im-)polite speech acts, yet paradoxically not many studies have been addressing the role played by face within the very speech act of evaluation (notable exceptions from the perspective of conversation analysis regard the so-called role of territory of information, see in particular Kamio 1997; Heritage 2012). This study addresses face-work in interaction by focusing on utterances where S evaluates some state of affairs and the degree to which s/he intends to overtly problematise or prevent H's reaction to potential face enhancing or face threatening speech acts. In this sense, despite not having been designed for usage-based analysis, Spencer-Oatey's taxonomy can fruitfully inform a corpus-based annotating scheme addressing S's overt attempts to maintain, enhance or challenge his/her ongoing rapport with $\mathrm{H}$. A systematic classification of this will be illustrated in section 3.1 and operationalised in section 3.2.

\subsection{Evaluative speech acts and pragmatic marking}

An important device to overtly account for face-awareness and Spencer-Oatey's taxonomy of rapport management is pragmatic marking. Pragmatic markers (henceforth PMs) are often described as markers that are multifunctional, acting as instructions or "linguistic 'road-signs' to intended meaning" and are in this sense "procedural" (Hansen 1998: 199; Waltereit 2001). This is where clause-periphery often comes into play as a formal diagnostic of analysis. For instance, epistemic predicates such as I think/believe being are "variable in their effect on truth conditionality" depending on their prosody and especially their position in the clause (Dehé and Wichmann 2010a: 18). It has been noted that truth-conditional functions characterise the usage of evidentials such as $I$ hear or evidently (Ifantidou 1994). Even in such cases, clause-periphery is a solid diagnostic for 
assessing their procedural function taking scope over the whole clause. Procedural meanings encoded at clause periphery intersect with speech act oriented modality and intersubjectivity (i.a. Sweetser 1990; Narrog 2012).

Notably, intersubjectivity is addressed from a number of different perspectives in the literature (i.a. Nuyts 2001, 2012; Verhagen 2005; Author 2013, 2017). Verhagen (2005) intends it as the coordination of cognitive systems between S and H. Nuyts (2001; 2012) approaches intersubjectivity as a dimension which can be shared between a speaker and hearer or not, rather than the way in which it is coded. Such a model informs Author's (2013, 2016b, 2017a, 2017b) gradient model intersubjectivity, which ranges from immediate awareness of another mind to extended awareness of a general 3rd party and social cognition.

As the present study is centred on the role played by face-management in evaluative speech acts, we will mainly rely on Traugott's working definition, which distinctively tackles "the way in which natural languages, in their structure and in their manner of operation provide for the locutionary agent's expression of his or her awareness of the addresses's attitudes and beliefs, most specially their 'face' or "self-image"' as an overtly codified mechanism (Traugott 2003:128). Simply put, in Traugott's view, intersubjectivity is an overt sign of awareness of H's face in interaction.

Functions of language that are most likely to mark the S's attention to the intersubjective face of the interlocutors are often related to politeness and meta-discursive functions such as turngiving, agreement-seeking or elicitation of response (Traugott 2012: 10). Concerning the identification of and clause-peripheral PMs, Traugott takes the position that, all contextual variables being equal, when meta-discursive and peripheral "uptake by another interlocutor appears on a regular basis in [the same genre of] texts, then the marker is being used intersubjectively" (Traugott 2012: 10). This has been the case of research centred on peripheral usages of clearly and no doubt developing intersubjective meanings between the 16th and the 18th century, or turn-taking devices and question tags soliciting a response by the hearer such as clause final right? in and is it not?, isn't it? and similar ones (Tottie and Hoffmann 2006; Traugott 2012: 11). As it will be specifically illustrated in sections 3, sentence peripheral presence of PMs constitutes an overt sign of rapportmaintenance in our corpus-based annotating scheme.

\subsection{Intersubjectivity as a marked dimension of rapport-maintenance}


From a usage-based perspective, it seems reasonable to account for the Spencer-Oatey's notion of rapport-maintenance (see point 3 in table 1) as a dimension of Traugott's intersubjectivity. Intersubjectivity indeed underpins S's attempt to account for H's face and, in turn, the projection of H's conceptualisation of S's face. As a usage-based mechanism, intersubjectivity is identified as an overt dimension that is often communicated via PMs and idiomatic formulae showing a formal tendency to occur in a clause-periphery position. Clause-peripheral PMs such as you know or believe it or not (i.a. Erman 2001; Tree \& Schrock 2002; Author 2017a, 2017b) profile S's awareness of $\mathrm{H}$ together with S's projected self as seen from H's perspective. This mirrored aspect of intersubjectivity is compatible with Goffman's original interest on communicated awareness of face coded as a spontaneous mechanism $(1955,1967)$. He distinctively stressed the "involvement in the face of others that is as immediate and spontaneous as the involvement he has in his or others' face" (Goffman, 1967:6). This is when S finds necessary to encode his/her awareness of H's as a distinctive effort or 'surplus' over mere propositional meaning and 'politic' behaviour (e.g. Gouldner 1960; Kasper 1990; Watts 2003; Culpeper 2011; Author et al. 2017c): e.g. Actually. I'm tired now vs. I'm tired now (cf. Traugott \& Dasher 2002; Author 2017a on the intersubjective functions of the discourse markers actually).

In some cases, the intersubjective 'surplus' of peripheral PMs may be characterised by a 'division of labour' between right and left periphery. Downing (2001) observes that second-pronoun right-peripheral usage of surely in evaluations such as in (3) below has a challenging "fighting word" function:

(3) Oh you can grate the cheese surely.

(Downing 2001:265)

Conversely, left peripheral employment of surely in evaluations intersects with seeking agreement or corroboration:

(4) Surely he must be worried?

(Downing 2001:268)

In both (3-4) above, $\mathrm{S}$ does not merely qualify the proposition in terms of dynamic and epistemic modality. The clause-peripheral employment of surely acts as a 'surplus' overtly codifying S's 
awareness of H's potential reactions to his/her evaluation $(\operatorname{Ev} F(\mathrm{p}))$, which directly intersects with their rapport-maintenance.

\subsection{Marked rapport-maintenance in Mandarin}

In Mandarin Chinese, the procedural function and the peripheral usage of intersubjective PMs is often matched by grammaticalised clause-final modal particles (语气词 yŭqìci). This point is particularly relevant, as Mandarin clause-final modal particles are operators of rapport-maintenance, as they are employed to overtly account for H's potential reactions to S's utterance.

In fact, most Sinitic languages make use of clause-final modal particles to express a variety of (inter-)subjective attitudes on the part of the speaker (Chappell \& Peyraube 2018). These are not obligatory (cf. Bisang 1996: 535 on the issue of non-obligatoriness in the Chinese grammatical system), yet they are added as a 'surplus' at the end of the clause to "facilitate conversational interaction and collaborative "production", coding emotions as varied as surprise, exasperation, indignation, and impatience, not to mention conveying the desired or perceived role relationship between speaker and addressee” (Chappell \& Peyraube 2018: 321). For instance, the particle 吧 ba "is used to code suggestions" (Chappell \& Peyraube 2018: 323) or invite H to take part to a physical or 'epistemic' co-action (Author 2017a). Its intersubjective nature is determined by its function to check or confirm that the addressee accepts the validity of the given proposition. In the case below, the speaker (S) does not recall the precise time of arrival at a holiday camp, but evaluates that 10 o'clock would be a reasonable guess and checks for the addressee's acceptance:

我们一到那儿的时候可能十点吧。

wǒmen yī dào nàer de shíhou kěnéng shídiăn ba

we once arrive there DE when probably ten-o-clock BA

'When we got there it was maybe around 10 o'clock, isn't it?'

(adapted from Chappell \& Peyraube 2018: 323)

Interestingly, similar to (3-4), in (5) S does not merely make an evaluation ( $\operatorname{Ev} F(\mathrm{p}))$ limited to the modal qualification of the state of affairs. With the overt employment of 吧 $b a$ s/he additionally 'takes care' of his/her rapport with $\mathrm{H}$ by endorsing her/him with the authority (and possibly the intention) of confirming the state of affairs that $\mathrm{p}$ describes. 
Another frequent particle is 啊 $a$ (or 呀 $y a$ ), which “has a hortatory use in prompting or urging the addressee to carry out the action desired by the speaker" (cf. Chappell \& Peyraube 2018: 323 ) and it is often used among people of close relations or even to set up close relations. When it is employed epistemically, 啊 $a$ emphasises S's subjective certainty while soliciting H to acknowledge the state of affairs of p (i.a. Xu 2007):

（6）我动手拉她, 背对着她姨妈什么的, 瞪眼小声道: “别来劲啊！”

wǒ dòng shǒu lā tā, bèiduì zhe tā āma shénme de, dèngyăn xiăoshēng dào: bié láijìn a I move-hand pull her, turn-back-to something DE, stare low-voice say: "do-not excited A" 'I moved my hand to pull her, I kind of turned my back to her aunt and said with my eyes wide open: don't get too excited ok?!'

(Adapted from Xu 2007: 144)

Modal particles themselves are often discussed as markers of evaluation (Doherty 1987). They can be considered as a grammaticalised sub-class of PMs, which beyond having scope over the whole clause and not carrying stress, do meet additional criteria such as not being used to form sentences in isolation or not allowing to be coordinated (i.a. Hansen 1998: 42-44; Waltereit 2001). As the degree of grammaticality of peripheral items in AE and Mandarin tends to vary significantly, from our dataset we identified intersubjective PMs based on clause-peripheral position and procedural functions, e.g. underpinning (im-)politeness, modality, turn-giving, agreement-seeking or elicitation of response. We thus included in our annotation a categorical variable referring to PMs appearing either at the beginning or at the end of the clause. In our scheme, the presence of such elements is an overt indicator of S's rapport-maintenance (RM) intentions as s/he opts for a codified 'surplus' of meaning, being expressed specifically to acknowledge H's potential reactions to the utterance.

\section{Data retrieval and analysis}

For our survey we relied on the comparable Callhome ${ }^{2}$ spoken corpora of Mandarin Chinese and American English, each of them consisting of 120 unscripted telephone conversations between native speakers, comprising 250000 words.

\footnotetext{
${ }^{2}$ https://talkbank.org/access/CABank/CallHome/zho.html ; https://talkbank.org/access/CABank/CallHome/eng.html (Last accessed 7/04/18).
} 
All collocates that have been included in our survey are corpus-driven and correspond to evaluative utterances including a modal auxiliary encoding either epistemic (pertaining to the evaluation of the chances that a certain hypothetical state of affairs [...] will occur, is occurring or has occurred in a possible world, cf. Nuyts 2001: 21), deontic (pertaining to rules and obligations), dynamic (pertaining to someone's dispositions, to situations or circumstances) or boulomaic meanings (pertaining to 'wants') (cf. Narrog 2017: 89 for a detailed taxonomy of non epistemic modal meanings). We aimed at a corpus-driven retrieval of most frequent modalised evaluative utterances from respectively the Mandarin and the AE Callhome corpora. To do so, we identified the three most frequent modal auxiliaries used in the two corpora, respectively could $(1,002.42$ per million words, henceforth pmw), should (459.24 pmw) and would (1,878.92 pmw) for AE and 会 hui 'to be able / to be the case that'(1,583.48 pmw), 可以 kěyi 'to be allowed / to be in the conditions of'(2,250.88 pmw) and 要 yào 'to want / must' (6,060.05 pmw) for Mandarin. Concerning this retrieval method, it is fundamental to stress that our aim was not to compare the meanings of the modal auxiliaries in Mandarin and $\mathrm{AE}$ as such, but rather to account for the relationship between highly frequent modalised evaluative utterances and face-management in the two languages. In this sense, primary meanings and polysemies of the modal auxiliaries from the Chinese and the AE corpora were not necessarily expected to match. Conversely, our intention was distinctively to account for modalised evaluative utterances that are most representative in each language - given the high contextual comparability of the two corpora - and the way such utterances would overtly intersect with face-management. We manually annotated twice all the 1200 spontaneous utterances that we retrieved from the Callhome corpora and assessed the meaning of each modal usage based on Palmers' (2001) taxonomy.

\subsection{Annotation and usage-based operationalisation of the criteria}

We designed a two layered annotation scheme to account for face-work occurring as an interactional phenomenon in the two languages. The first layer would impinge on rapport, viz. whether S aims at maintaining (RM), enhancing (RE), challenging (RC) or whether s/he simply neglects $(\mathrm{RN})$ his/her rapport with $\mathrm{H}$ whilst making an evaluation.

The second layer of analysis would underpin whether S overtly expresses a positive or negative evaluation of $\mathrm{H}$. This is what we define as propositional face-work, which we suspected to be an important subcategory of face-management when cross-cultural comparison is at stake. The 
novel notion of propositional face-work directly regards whether FTAs or FEAs result from the very evaluation that the speaker makes about the Addressee (coded in table 1 as pFTA and pFEA). Our corpus-driven annotation scheme was based on the following usage-based taxonomy, specifically intending to capture overt signs of rapport-management in interaction:

\begin{tabular}{|c|c|}
\hline Tag & Rapport-orientation \\
\hline RE & $\begin{array}{l}S \text { makes the attempt to improve his/her rapport with } H \text {. S/he says something that is } \\
\text { advantageous for } H \text { (e.g. proposes something that may be beneficial for him/her: "you could } \\
\text { do } p, p \text { would be good for you"). }\end{array}$ \\
\hline $\mathrm{RE}+\mathrm{pFEA}$ & $\begin{array}{l}\text { S overtly says something that boosts } H \text { personal/social image (e.g. appraisals, positive } \\
\text { comments). }\end{array}$ \\
\hline $\mathrm{RM}$ & $\begin{array}{l}\text { Sovertly codifies his/her awareness of H's potential reactions to the utterance. This intersects } \\
\text { formally with presence of clause-periphery intersubjective markers (PMs) and peripheral } \\
\text { periphrastic strategies. }\end{array}$ \\
\hline $\mathrm{RN}$ & S makes an evaluation without any overt element of RE or RM. \\
\hline $\mathrm{RC}$ & $\begin{array}{l}\text { S utters something that is disadvantageous to } H \text { (e.g. gives an overt order, accuses or exerts } \\
\text { some form of power over } H \text { ). }\end{array}$ \\
\hline $\mathrm{RC}+\mathrm{pFTA}$ & $S$ overtly says something about $H$ that downgrades his/her personal/social image. \\
\hline
\end{tabular}

Table 1.

Criteria for the usage-based identification 6 different layers of face-work

It is fundamental to note that the nature of this project is inherently usage-based. This entails that the annotation was entirely determined by interactionally marked elements making overt the taxonomy in table 1. This methodology was thus not aimed at 'interpreting' the feelings of the single interactants during their conversation, but rather identifying linguistically overt means of rapport management. Our operational method of annotation is discussed in the next section.

\subsection{An operational annotation of rapport management and propositional face-work in interaction}

This section aims at providing a few examples from our dataset that can illustrate the annotation scheme in table 1. Annotation labels from table 1 appears on in chevron $(<>)$ at the top of each example (or group of examples). When needed, some additional context is given in squared brackets ([ ]). We can start from two cases of RE (rapport enhancing) in (7-8) below: 
[S suggesting $\mathrm{H}$ to find some job after the university]

（7）然后你再想干别的呀，什么的，你这也可以走喔，很好的。

ránhòu nǐ zài xiăng gàn biéde ya shénme, nǐ zhè yě kěyř zǒu wō, hěn hăo de

then you again think do other YA, something, you this also can walk O, very good

'Then if you feel like doing something different, you can also leave isn't it? Which is pretty good.'

Callhome/CHIN/1525

(8) A: I could go to Buffalo.

B: I was going to uh say you could do that. And we could drive.

Callhome/ENG/4432

In (7) above $\mathrm{S}$ makes an attempt to enhance his/her rapport with $\mathrm{H}$ : s/he makes an evaluation with 可以 kěyı̌ to make a suggestion that is ultimately beneficial to $\mathrm{H}$. The presence of the modal particle 喔 $\bar{o}$ makes overt S's monitoring of H's reactions to her utterance3. Something similar occurs with could in (8B) whereby $\mathrm{S}$ evaluates a possibility that would be ultimately beneficial to $\mathrm{H}$. In our scheme, RE utterances are valid when they are potentially compatible with following evaluations stressing a positive conditional outcome from H's perspective, e.g. that would be good for you.

$<\mathrm{RE}+\mathrm{pFEA}>$

[referring to H's ability to play the piano]

（9）单调的也挺好么, 那你会啦!

dāndiào de yě tǐnghăo me, nà nǐ huì la !

monotonous DE also very good ME, so you can LA

'A monotonous style is also pretty good come on, so you actually can play it!'

Callhome/CHIN/1396

\footnotetext{
3 It is important to note that RE utterances that include PMs as overt markers of intersubjectivity and are a hypercategory or RMs. When that was the case, in our dataset they would simply appear as RE, while in a separate column we distinctively would account for the 'categorical' presence of PM as a separate variable.
} 
In (9) above, S's overt management of his/her rapport with $\mathrm{H}$ is marked by the presence of clauseperipheral PMs of cooperation, respectively 嘛/么-ma/me and 啦-la. In addition to that, s/he boosts the personal/social image of $\mathrm{H}$ by positively evaluating his/her skills at the propositional level, i.e. $\mathrm{s} /$ he praises $\mathrm{H}$. This is an instance that in our dataset is marked as RE as well as pFEA (propositional face-enhancing act). Utterances marked as RE + pFEA are potentially compatible with subsequent evaluations further boosting $\mathrm{H}$ 's personal/social image, e.g. you are pretty good, 你很 棒 nı̌ hěn bàng 'you are amazing'. They are operationally distinct from bare RE (e.g. (7-8) above), as they are not compatible with comments such as *that would be good for you.

$<\mathrm{RM}>$

[S explains that there is no need to send all the tapes together at once]

（10） 九盘磁带么, 我可以分开来寄啊。

jiǔ pán cídài me wǒ kěy̌̌ fēnkāi lái jì a

nine CL 4 tape ME I can separate come send $\mathbf{A}$

'Well, we are talking about nine tapes, you'll agree I could send them separately.'

CallHome/CHIN/0114

(11) Well, if I wanted to have a child I should do it you know and so that pushed me.

Callhome/ENG/4571

(12) I mean she couldn't say to Judith no they can't come that week.

Callhome/ENG/4610

While making an evaluation in (10), S employs the clause peripheral PM 啊 $a$ to make overt his/her intention to account for H's stance and expects him/her to finally agree with $\mathrm{p}$. This is also the case in (11-12) where $\mathrm{S}$ does not barely evaluate $\mathrm{p}$ modally, but also overtly 'accounts' for his/her rapport with $\mathrm{H}$ and her potential reactions to his/her evaluation with clause peripheral PMs well and you know, viz. s/he negotiates the 'common sense' of her statement (see Author 2013, 2017a about immediate vs extended construals of intersubjectivity). Intersubjective PMs such as well, you know and I mean all tend to occur very frequently in conversation as they are tied to the naturalistic, unrehearsed and collaborative nature of spontaneous talk (i.a. Fox Tree 1999; Fox Tree \& Shrock 2002). Evaluative utterances labeled as RM (rapport maintaining) can operationally identified as they formally include peripheral PMs of intersubjectivity. In addition to that, they are not

\footnotetext{
4 Classifier.
} 
compatible with ensuing comments impinging on either H's advantageous conditions, nor to his/her social/personal image, such is the case of respectively RE (7-8) and RE+pFEA in (9).

$<\mathrm{RN}>$

(10) 退休的话, 我收入, 暂时不会少。

tuìxiū de huà, wǒ shōurù, zànshí bù huì shăo

Retire DE word, I income, temporarily not it-is-the-case little

'If I retire, my incomes won't be too little for now.'

CallHome/CHIN/0823

(11) I could'n- have writ-, I could not have written that script.

CallHome/ENG/4686

Utterances labeled as RN (rapport neglecting) express a modal meaning without any overt codification of $\mathrm{H}$ as an interactional persona, viz. they do not include conventionalised PMs of intersubjectivity, nor they overtly express any evaluation that is connected to H's personal or social image. Examples (10-11) are illustrative of this category.

$<\mathrm{RC}>$

[Two educators discussing about 'tenure' files]

(12) You should not be cutting corners on putting that file together.

CallHome/ENG/4610

[Parents are not willing to let their son to work in a restaurant]

（13） A: 那你要来, 让你去打那工, 我们也不会让你去打哎。

nà nǐ yào lái, ràng nǐ qù dă nà gōng, wǒmen yě bù huì ràng nǐ qù dă āi

then you if come, let you go hit that job,we also not it-is-the-case let you go hit AI

'Then if you come, when it comes to us letting you go to work there, well that is not gonna be the case!'

$B$ : 你不让我打, 我也得打啊。

nǐ bù ràng wǒ dă, wǒ yě děi dă a

you not let me hit, I also must hit A

'Well, I must do it even if you don't let me!' 
$\mathrm{RC}$ (rapport challenging) are cases where $\mathrm{S}$ makes an evaluation that may have a negative impact on his/her rapport with $\mathrm{H}$. This is the case of (12) where $\mathrm{S}$ makes an evaluation that carries a form of deontic meaning that exerts some form of power over H. Similarly, in (13A) S overtly makes an evaluation that directly affects H's negative face, inhibiting his/her freedom of action and autonomy. In $\mathrm{RC}$, there is a frequent intersection between modalised evaluations and negative polarity. RC are compatible with preventive apologies or ad-hoc formulae preparing $\mathrm{H}$ to hear something more or less discomforting such as, frankly, I am sorry but $\mathrm{p}$, I have to tell you that $\mathrm{p}$, 对不起, 可是 duì bù $q \check{l}$, kěshì 'I am sorry, but', 我跟你说 wǒ gēn nǔ shuō 'let me tell you'. This type of mitigating formulae (at times also anaphoric) are clearly not compatible with REs, RE+pFEAs or bare RMs.

\section{$<\mathrm{RC}+\mathrm{pFTA}>$}

[S complains about $\mathrm{H}$ not wearing slippers at home]

（14）你那个, 你那个鼻子会, 会有䖝子, 我跟你说。

nǐ nà ge, nǐ nà ge bízi huì, huì yǒu shīzi, wǒ gēn nǐ shuō

you that CL, you that CL nose it-is-the-case-that it-is-the-case-that have louse, I with you say 'Let me tell you, you will have louses growing in your nose!'

Callhome/CHIN/4571

Finally, in (14) above S utters something potentially challenging H's face at the propositional level. When $\mathrm{H}$ is the 'target' of S's negative evaluation, the utterance is marked as RC+pFTA (rapport threatening act) in our scheme.

Our annotation aimed at capturing holistic patterns of usage which would additional include semantic and syntactical dimensions encompassing evaluations in the two datasets. As a result, we additionally took into account:

- the modal meaning of each lexeme we queried;

- whether the employment of a modal verb would intersect with positive vs negative polarity;

- which (if any) PMs would appear in a sentence periphery position;

- whether the sentence would include a syntactic subject;

- $\quad$ whether evaluations would formally include a speaking subject (i.e. a first person pronoun). 
All the columns of our spreadsheet are illustrated below, with one sampled collocate of could (corresponding to (12) above ) out of all the 1200 annotated evaluative occurrences:

\begin{tabular}{lllllllll}
\hline lexeme & speak_subj & synt_subj & sent_p_PM & PM & polarity & modal_m & rapport & $\begin{array}{l}\text { p_face- } \\
\text { work }\end{array}$ \\
\hline Could & no & yes & yes & I_mean & neg & dyn & RM & absent \\
& & & Table 2. & & &
\end{tabular}

Sampled row of annotation from our dataset

All 1200 occurrences from our dataset have been through double-blind annotation based on the criteria given throughout this section, with a matching rate of $87 \%$. Remaining collocates have been disambiguated after a third round of annotation from a third annotator. All collocates that were not evaluative speech acts (e.g. 要 yào occurring as a connector instead of an epistemic predicate) were manually excluded from our samples. Missing observations of any of the 6 lexemes we queried were then replaced from a randomised sample from our annotated dataset, with a final spreadsheet counting 200 observations for every lexeme in each language.

\section{Illocutional concurrences and illocutional complexity}

This section provides the three main case-studies of this work: a cross-linguistic analysis of propositional face-work (4.1), a conditional inference tree and random forest modelling of illocutional concurrences and illocutional complexity of evaluations in the two languages $(4.2,4.3)$ and a comparative multiple correspondence analysis tackling the relationship between evaluative speech acts and sentence-periphery marking (4.4).

\subsection{Propositional face-work}

The first important mismatch emerging from our survey regards the category of propositional facework, viz. whether S would overtly make a positive or negative evaluation targeting H's. 

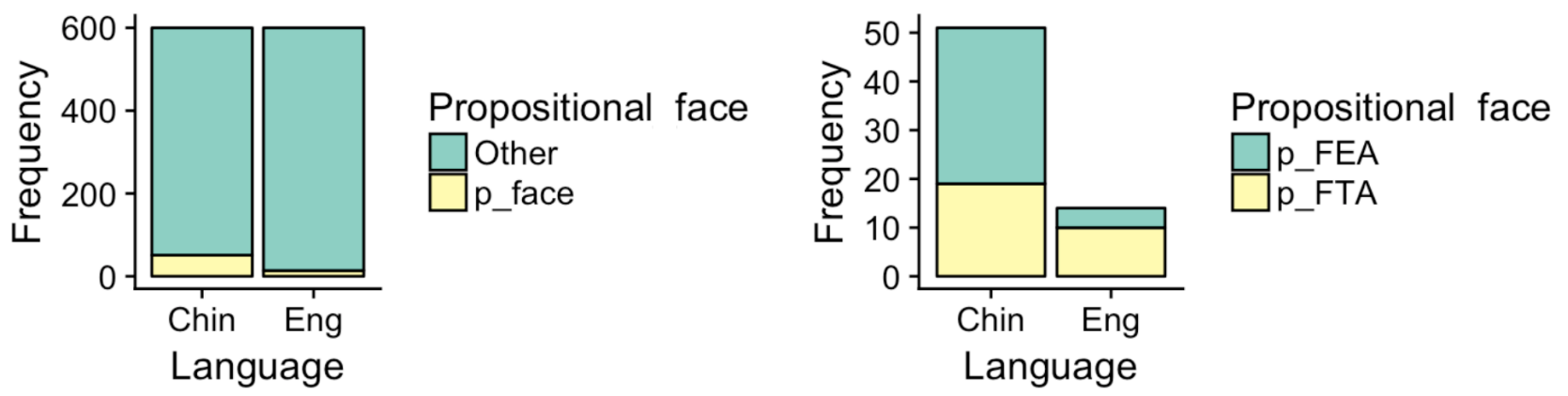

Figure 1.

Propositional face-work in Spoken American English and Mandarin

The two plots in figure 1 above account respectively for propositional face-work occurring in the two languages as a general phenomenon (left-hand side) and for propositional face-work occurring as face enhancing (FEA) as opposed to face threatening (FTA) (right-hand side). While, predictably, only a small amount of evaluations from our samples would overtly target the $H$, nonetheless there is a significant mismatch between the two corpora, with 51/600 cases in Chinese and only 14/600 in English (Pearson's Chi-squared test $\mathrm{p}<000.5$ ). Interestingly, it also worth noting that propositional face tends to occur more frequently in the form of FEA (32/51) in Chinese, while FTA (10/14) is preponderant in $\mathrm{AE}$ (despite the limited number of occurrences of the latter). This mismatch also led to a significant result, Pearson's Chi-squared test $p<0.05$. To summarise, two important insights emerge from this first analysis:

a. From our context-dependent data, propositional face-work is a more prominent category in Mandarin than in AE.

b. From our context-dependent data, Chinese propositional face-work significantly occurs more frequently in the form of FEA. Conversely, when it occurs in AE, it tends to be comparatively more frequent in the form of FTA.

In (15) below is reported an instance of RC+pFTA in American English:

$<$ RC+pFTA $>$

[B is informing A s/he has made the decision of taking one semester off from classes]

(15) Well, once your tenure file goes in I'll be ready to believe that but until you get it in. I, I don't think you should have. 


\subsection{Illocutional concurrences: A conditional inference tree approach}

The main aim of this study is to shed light on evaluations as holistic, situated speech acts determined by formal and illocutionary patterns of usage, which we expect to vary crosslinguistically and cross-culturally. To achieve this, we plotted a conditional inference tree model (cf. Hothorn et al. 2006; Tagliamonte \& Bayen 2012) gathering unbiased corpus-driven convergences of form, meaning, context and pragmatic effects, all contributing to the spontaneous encoding of evaluations in the two languages (see table 2 in section 2.2). Significant intersections of the variables subsumed by these 4 dimensions is what we call illocutional concurrences (IC). Namely, ICs encompass converging factors at different levels of verbal experience that contribute, both locally (i.e. at the morphosyntactic level) and peripherally (i.e. at the illocutionary level), to the encoding of contextually and culturally situated speech acts or pragmemes (i.a. Mey 2001; Capone 2005; Author 2016a).

This method has the advantage of plotting statistically significant patterns of formal and functional variables intersecting hierarchically with one another. This allows us to reproduce computationally S's 'illocutional inclinations' leading to a number of distinctive convergences in the two languages.

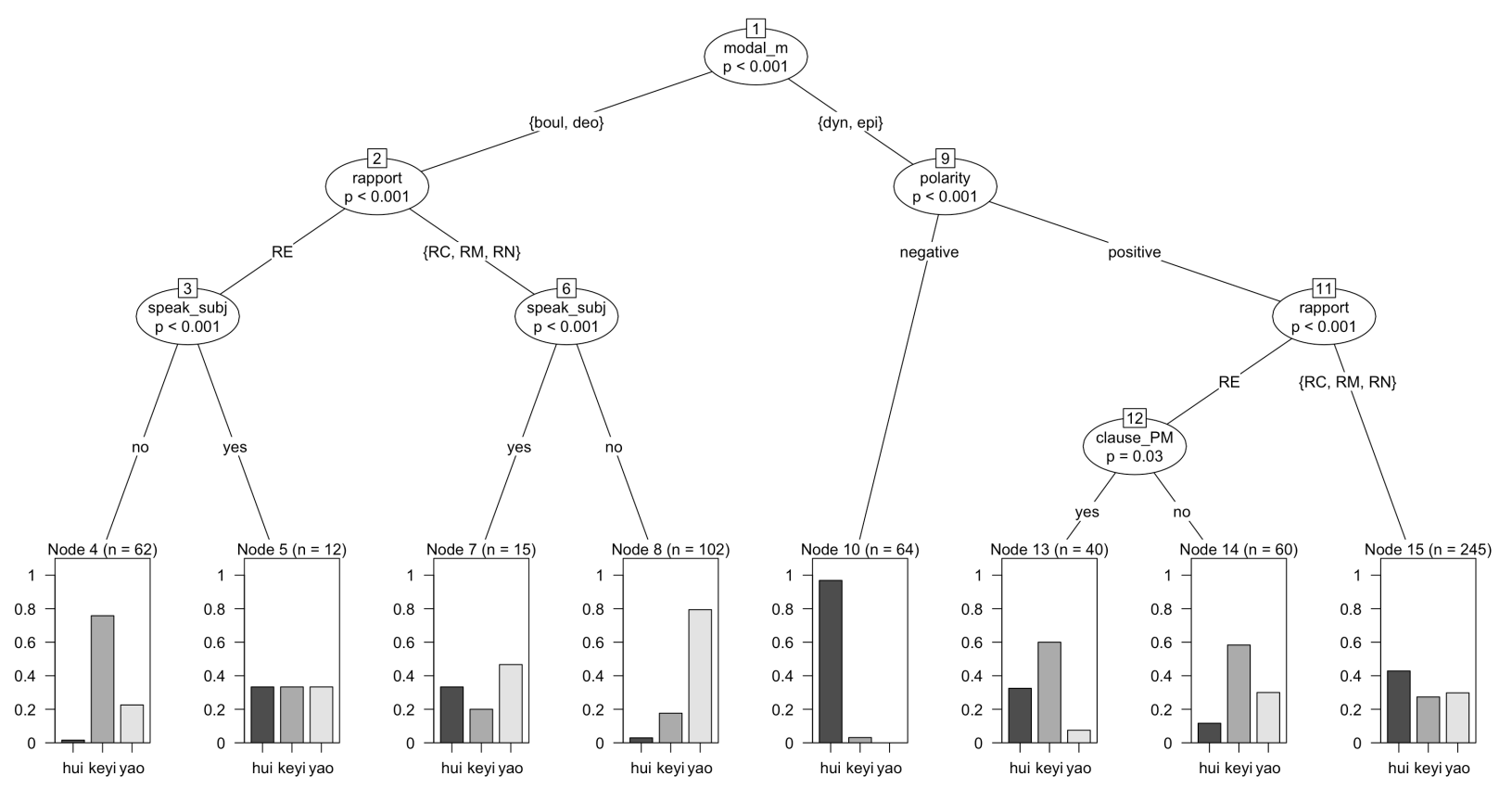

Figure 3.

Illocutional concurrences of evaluative speech acts from the CallHome of Mandarin Chinese 
The plot above is obtained with the 'ctree' function of the R package 'party' (cf. Levshina 2015: 291) and refers to ICs of the three lexemes 会 huì 可以 kěyı̌ and 要 yào in the CallHome corpus of Mandarin. As obvious as it may be, it is still important to stress that the tree above has nothing to do with a generative one. Conditional dependencies among variables in figure 3 exclusively depend on statistical significance, (the higher the node, the more significant the 'conditional decision'). They represent illocutionary context-bound inclinations among rapport management, propositional facework, modal meaning and the other variables that we introduced in section 2 . The descending order of each split computationally simulates a conditional 'decision' made by interlocutors based on degrees of significance of each covariant that comes into play when an evaluative speech act is realised. Simply put, the plot above is completely usage-based and computes holistically probabilities among semantic, pragmatic together with formal variables.

The first IC that is worth noting runs from node 1 to 4 and regards the evaluative usage of 可以 kěy̆̌, which significantly intersects with deontic modality, rapport enhancement (RE) and absence of a coded speaking subject: [deo $>$ RE $>$ speak-subj]. This IC is extracted from the original plot in figure 4 below:

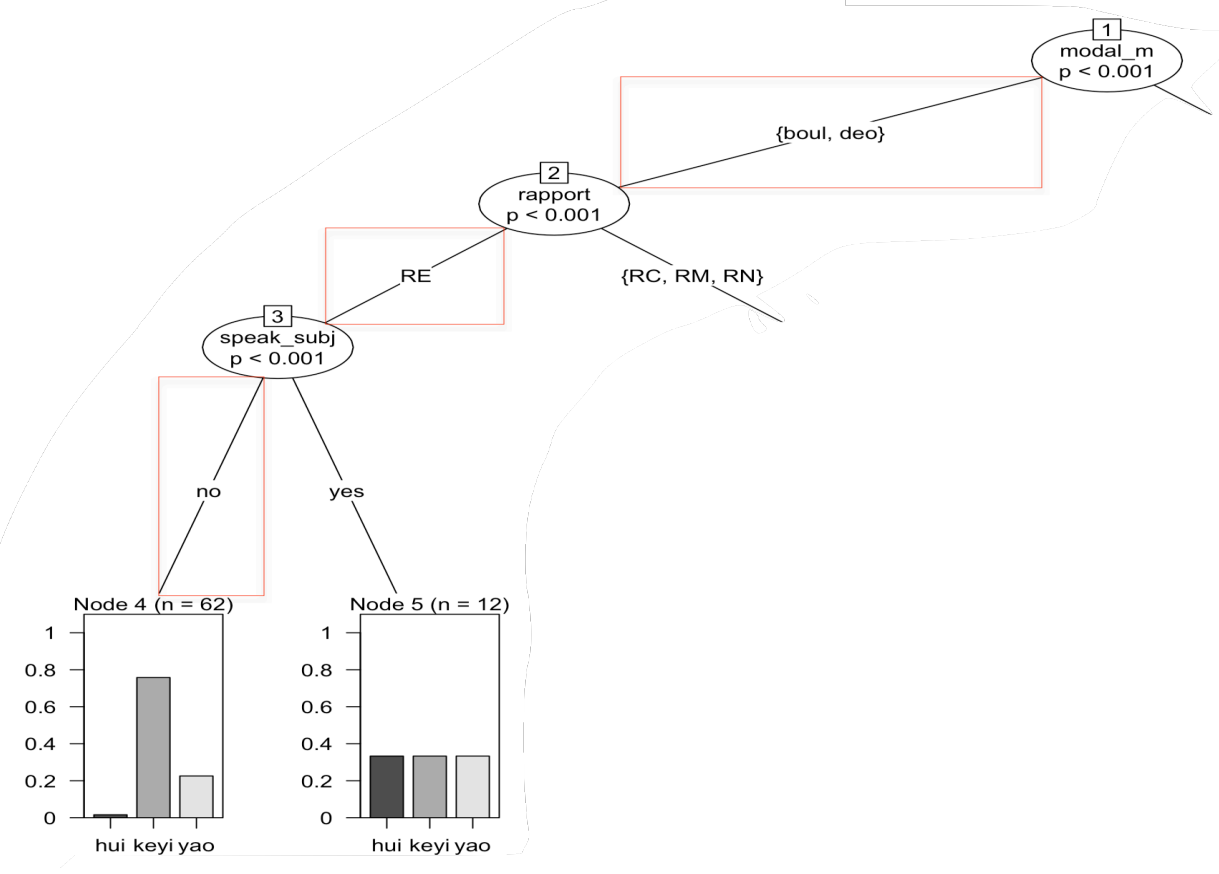

Figure 4.

One illocutional concurrence (IC) of 可以 kěyǐ: [deo>RE>speak-subj] 
This IC can be paraphrased as follows: when the modal meaning of a Mandarin evaluation is

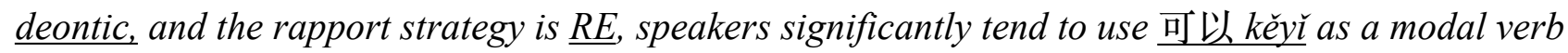
in absence of a speaking-subject (e.g. 我 wǒ 'I'). In fact, in our data 可以 kěyl often has a distinctive RE function in which S makes evaluations that entail permission or suggestions that are beneficial to $\mathrm{H}$ :

$<\mathrm{RE}>$

[H needs to send his/her personal details in a letter]

(16) A: 可以, 嗯, 你写过来吧。

kěy̌̌, ēn, nǐ xiěguòlai ba.

You definitely can, send it to me.

A second IC that is worth mentioning is the evaluative usage of 要 yào. It encompasses nodes 1-2-6-8 with boulomaic or deontic meaning, significantly not expressing RE in absence of a coded speaking subject: [\{boul, deo\}>RE $>$ speak-subj]: when the modal meaning of a Mandarin evaluation is deontic or boulomaic, and the rapport strategy is not RE, speakers significantly tend to use 要 yào as a modal verb in absence of a speaking-subject (e.g. 我 wò 'I'). This suggests a clear division of labour among the deontic usages of 要 yào and 可以 kěy̆, with the latter distinctively expressing a RE function.

There are two more ICs that deserve special attention. First, is the negative 不会 bùhuì 'not going to be the case/ not being able' (nodes 1-9-10) not being significantly affected by rapportmanagement when conveying dynamic or epistemic meanings: [\{dyn, epi $\}>$ negative]. Secondly, 可 以 kěyl again shows a distinctive RE function, in this case with dynamic or epistemic usages, positive polarity and specifically in the presence of peripheral PMs (nodes 1-9-11-12): [\{dyn, epi\} $>$ positive $>$ RE $>$ clause_PM].

\subsection{Illocutional complexity}

We can now compare the results from the conditional inference tree of the Chinese data with figure 5, where are plotted the ICs from the CallHome of American English: 


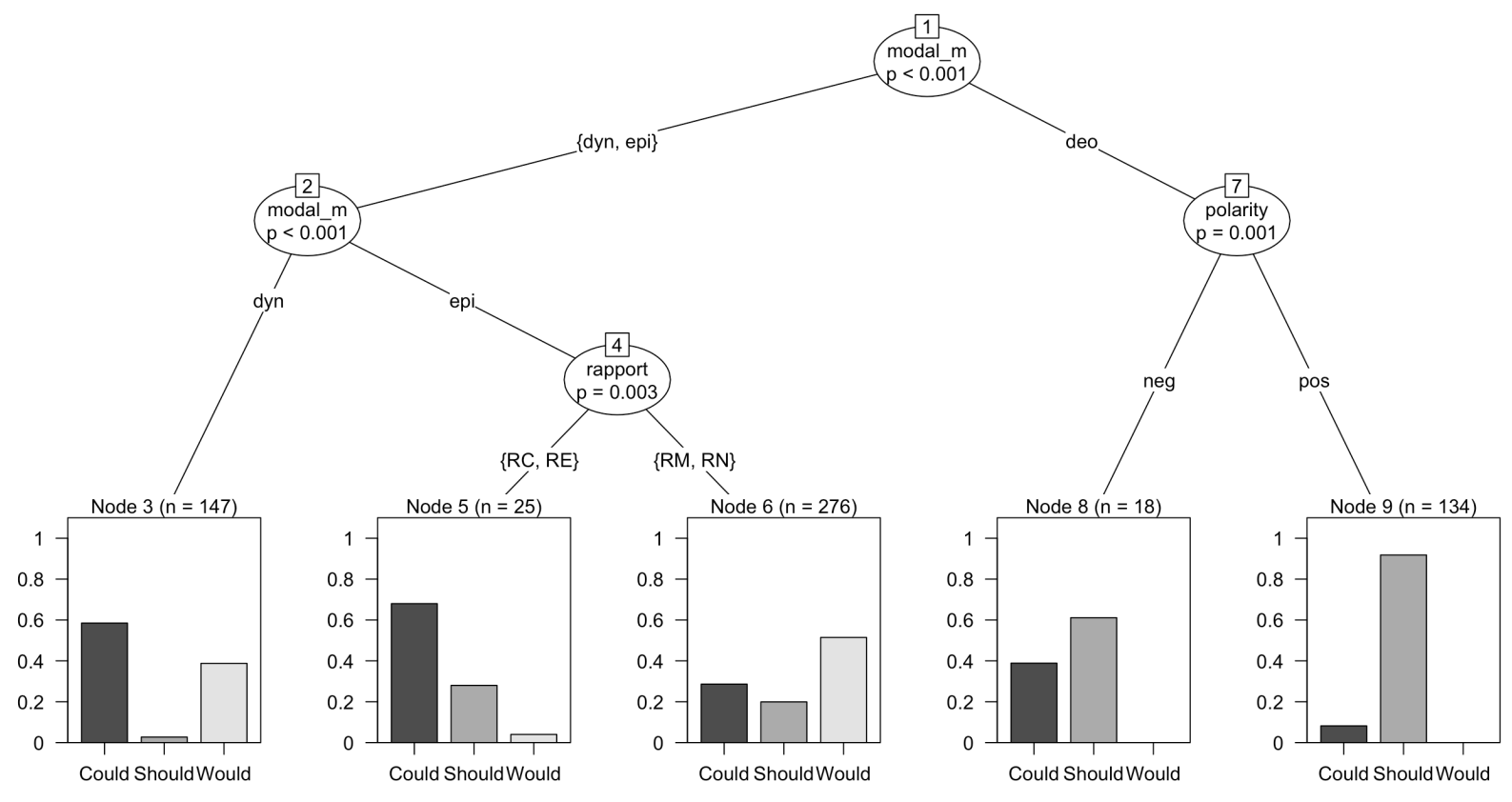

Figure 5.

Illocutional concurrences of evaluative speech acts from the CallHome of American English

First thing to be noted, the plot here appears much simpler, with less significant ICs encompassing rapport-management, distinctive presence/absence of PMs of intersubjectivity and so on. Beyond obvious semantic correspondences (e.g. should prominently used deontically), it is interesting to note that rapport-management tends to be significantly 'at-issue' only in epistemic usages (nodes 1-2-4), while this is not the case with deonticity.

Figure 5 above brings about an important issue of illocutional complexity, viz. the gradient intersection of overtly interactional variables that contribute to the encoding of a contextually and culturally situated speech act. The 15 nodes of figure 3 in contrast to the 9 in figure 5 suggest that evaluative speech acts in our Mandarin dataset are characterised by a higher illocutional complexity than what we can see in AE. This can be assessed more precisely with the aid of a random forest model, which can plot the conditional importance of variables after computing a number of conditional trees such as the ones in figures 3 and 5 . 


\section{Conditional importance of variables (CHIN)}

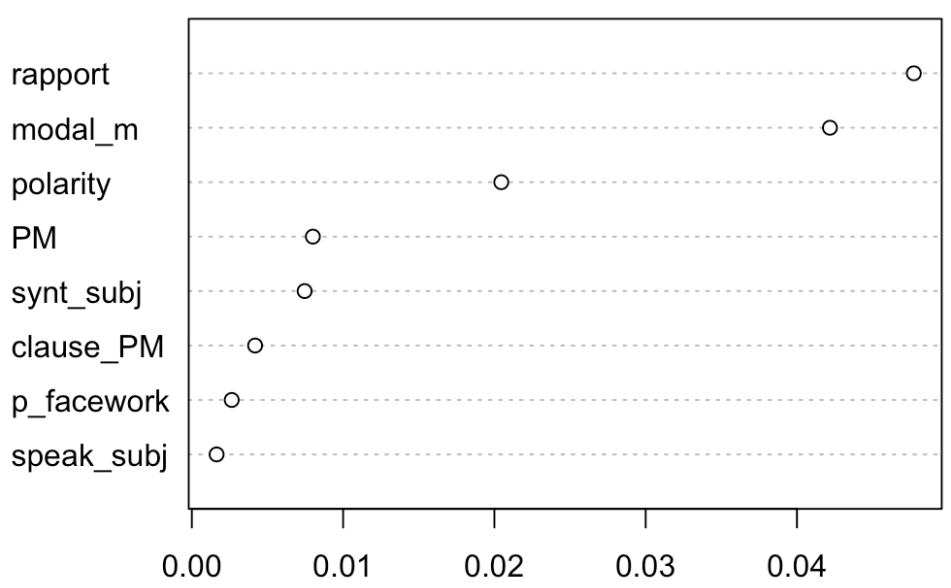

Figure 6.

Conditional importance of variables from the Chinese dataset

The variable importance scores demonstrate that rapport-management is the most important predictor (0.049) in Mandarin, followed by the modal meaning of the lexemes $(0.041)$, polarity (0.021), PMs of intersubjectivity (0.010), down to presence/absence of a coded speaking subject. While the cut-off value is the absolute importance value of the variable with the smallest score (cf. Levshina 2012: 298), none of the above yet corresponds to zero.

\section{Conditional importance of variables (AE)}

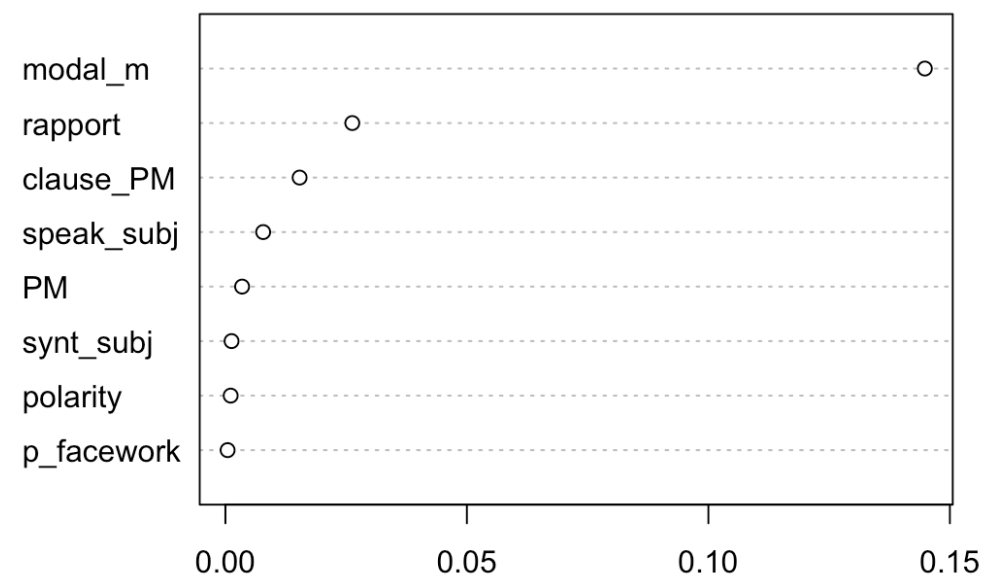

Figure 7.

Conditional importance of variables from the $\mathrm{AE}$ dataset 
Things differ for AE data in figure 7, where there is one outstanding predictor - which is essentially semantic - i.e. the modal meaning expressed by the three lexemes (0.145). Additional variables that marginally contribute to evaluations in AE are rapport (0.026), PMs of intersubjectivity (0.015) and presence/absence of a speaking subject (0.008), while quite a number of dimensions vary around zero.

All in all, the two plots above confirm that Mandarin evaluations in our data are characterised by a much higher illocutional complexity, as there is a much more varied number of interactional factors contributing to context-specific speech acts. Even more crucially, in the Chinese data the most important element that speakers overtly account for whilst making evaluations is inherently intersubjective, viz. rapport-management. This is in contrast with $\mathrm{AE}$ where the very semantic meaning of the lexemes (i.e. should, could, would) is alone by far the most important variable.

\subsection{Illocutional concurrences and sentence periphery: A multiple correspondence analysis}

The final analysis of this study concerns the relationship between evaluative speech acts and clause periphery marking in the two datasets. As mentioned previously, the dotchart in figure 6 highlights a number of important dimensions contributing to the encoding of evaluative speech acts in Mandarin. The top four are rapport-management, modal meaning, polarity and PMs of intersubjectivity. The high illocutional complexity and the varied system of garmmaticalised PMs of Mandarin is worth further digging into the specific interaction among these variables.

We thus plotted a multiple correspondence analysis (i.a. Nenadic \& Greenacre 2007) on a two-dimensional plane. In correspondence analysis modelling, associations among variables are unveiled by calculating the chi-square distance between different categories of the variables and between observations. These associations are then represented graphically as a map, which eases the interpretation of the structures in the data, the closer the distance between variables, the stronger the statistical correspondence. 


\section{Mandarin CallHome MCA plot}

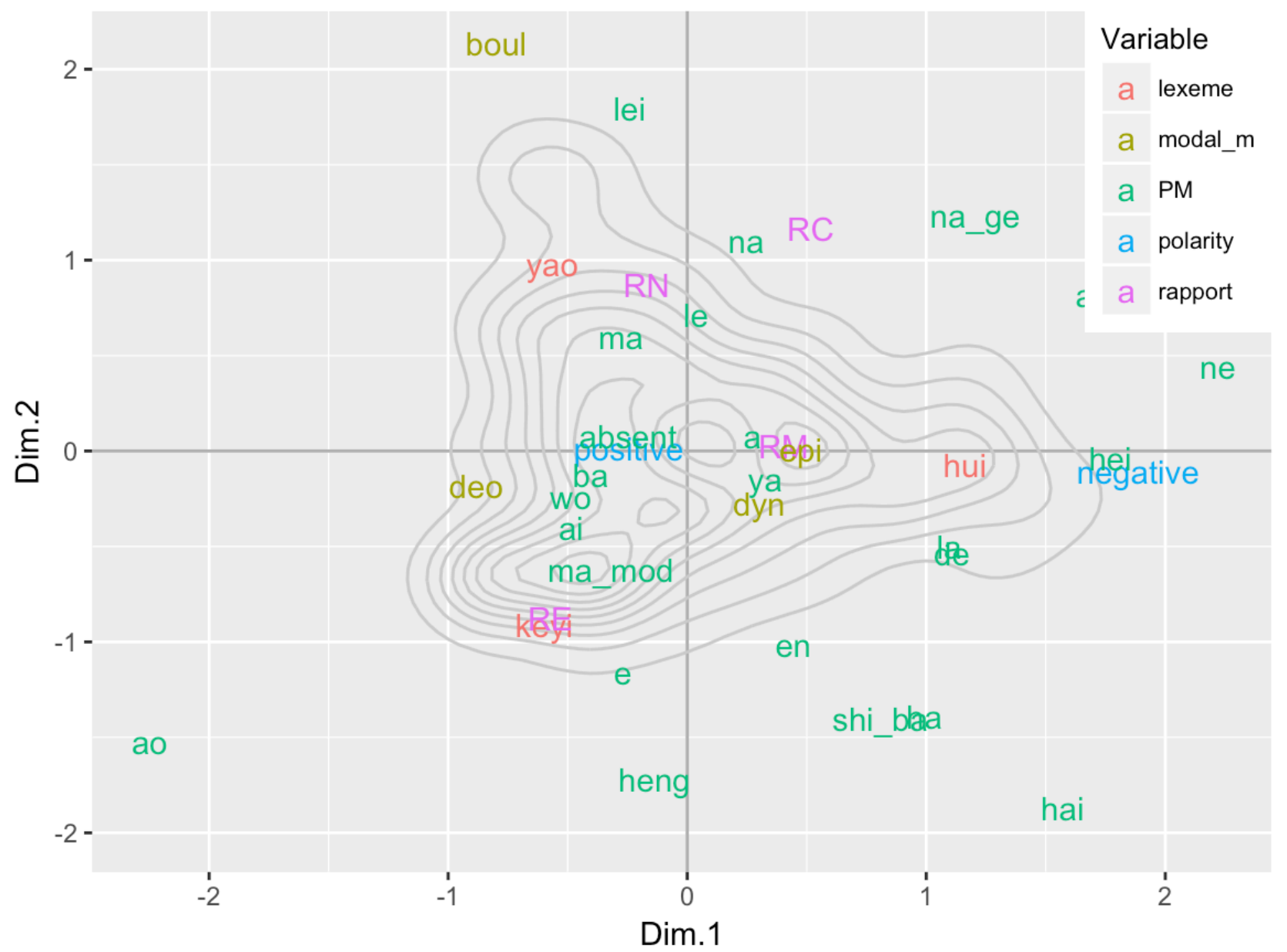

Figure 8.

Multiple correspondence analysis of rapport, modal meaning, polarity and rapport from the

Callhome of Mandarin

In this plot, the triangular distribution of areas of density follows the disposition of the three lexemes given in red 可以 kěyĭ, 会 huì and 要 yào. In the top-right corner are given the other variables that significantly affect the usage of the three lexemes: modal_m (modal meaning) in brown, PM (pragmatic markers) in green, polarity in blue and rapport strategies in purple.

We can immediately notice some ICs that we saw in the conditional inference tree, viz. a strong convergence of positive polarity with employment of 可以 kěyı̌ and RE strategies (Dim.1: -0.6, Dim. 2: -1). Additionally, we are now able to visualise the PMs with the highest associations with this particular IC on the map, i.e. 嘛 $m a$ ，吧 $b a ，$ 哎 $a i$ ，喔 $w o$, 呃 $e$ (see Xu 2007 and $\mathrm{Wu}$ 2012 for detailed illustration of Mandarin modal particles). Also, RC (rapport-challenging) utterances are outside the main areas of density (Dim. 1: 0.5, Dim. 2: 1.1), suggesting a stronger convergence between frequent PMs and other functions of rapport-management. This indicates that 
Mandarin speakers are unlikely to use clause final particles in strategies of rapport challenging. There is also a very strong association between epistemic evaluations and presence of RM (rapportmaintenance) strategies (Dim.1: 0.5, Dim. 2: 0), suggesting a marked interdependence between the expression of subjective opinions and the monitoring of H's potential reactions to the utterance in Mandarin.

One last point that is worth stressing is also one IC that we observed previously about 会 hui (Dim. 1: 1.1, Dim. 2: -0.1), being more likely to occur with negative polarity and comparatively less affected by peripheral PMs. Simply put, when 会 hui occurs to express future conjectures, it is often negated and less affected by peripheral PMs, see (17) below:

(17) 不会什么, 太有, 太大的变动。

bù huì shénme tài yǒu tài da de biàndòng

no it-is-the-case something too-much have too-big DE change

'there won't be too many changes.'

CallHome/CHIN/1359

We can now finally look at the multiple correspondence analysis of the top four variables of AE, also obtained from the random forest results in figure 7. 


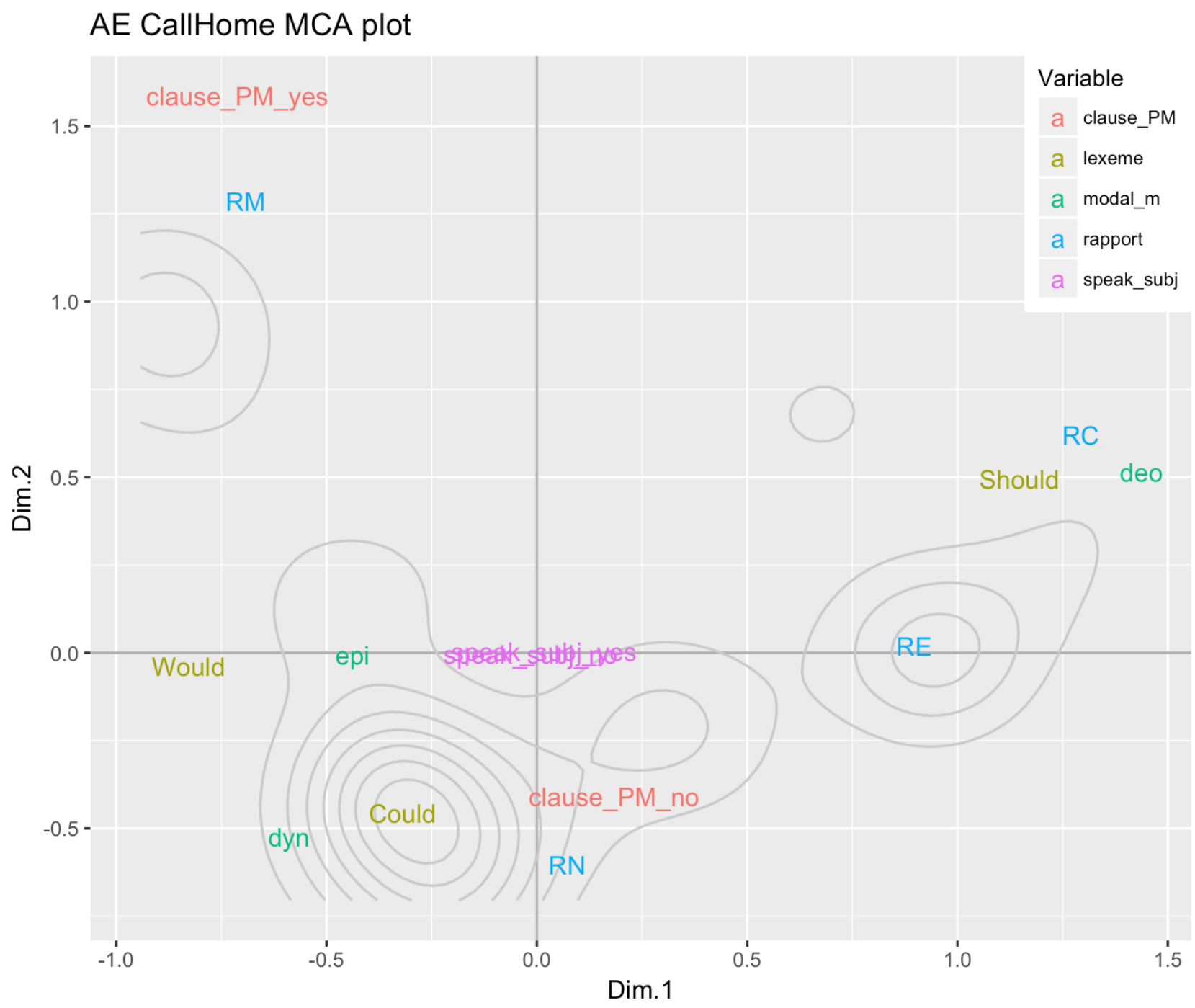

Figure 9.

Multiple correspondence analysis of modal meaning, rapport, coding of speaking subject and presence of PMs from the Callhome of AE

As expected, in contrast withs the Chinese data, here there is not as much interaction among variables. Once again, in the American English data predictable correspondences emerge among lexemes and modal meanings, e.g. should relatively closer to deonticity (Dim. 1: 1.3, Dim. 2: 0.5), while would and could comparatively closer to epistemic and dynamic polysemies. There is also a neat convergence of missing peripheral PMs, given in red as 'clause_PM_no' (Dim. 1: 0, Dim. 2: -0.4) with RN strategies. This clearly entails that rapport neglecting lacks overt PMs of intersubjectivity. On the other hand, RM (Dim. 1: -0.7 , Dim. 2: 1.3) is closely correlated with presence of peripheral PMs. One last important cross-linguistic mismatch that deserves attention is that all lexemes (would, should, could) here tend to be relatively closer to 'clause_PM_no' (Dim. 1: 0, Dim. 2: -0.4), in the sense of being more prototypically used in absence of peripheral PMs. This 
fundamental result clearly indicates that $\mathrm{AE}$ evaluations are less 'intersubjectively' marked than Mandarin ones with AE speakers being interactionally less concerned of H's potential reactions to their evaluations and potential damage to harmonious relations between the interlocutors.

\section{Conclusions}

This paper tackled the language-specific and multilayered relationship between evaluations and interactional face-work. We designed a novel usage-based model to identify context-bound and language-specific illocutional concurrences (IC). IC unveil converging factors at different levels of verbal experience. They define the encoding of contextually and culturally situated speech acts or pragmemes (i.a. Mey 2001; Capone 2005; Author 2016a), both locally (i.e. at the morphosyntactic level) and peripherally (i.e. at the illocutionary level). Conditional inference tree modelling, together with complementary methods of context-dependent data-manipulation led to 4 general results:

a. The notion of propositional face-work underpins $\mathrm{S}$ overtly making a positive or negative evaluation of H's persona. This emerged to be a more prominent category in Mandarin than in AE: Mandarin speakers are more likely to make evaluations that directly target their interlocutors.

b. Mandarin evaluations are characterised by higher illocutional complexity. The latter depends on the variety and the number of interactional factors (nodes) contributing to context-bound speech acts. They go beyond mere modal qualification of the state of affairs, as they tend to change formally depending on which IC is at stake (e.g. systematic employment of PMs to account for RM; significant absence of PMs in contexts of RC; omission of speaking subject when specific lexemes such as 可以 kěyľ are used for RE, and so on). AE evaluations are comparatively less 'marked' for dimensions that go beyond mere propositional meaning, and thus less complex at the illocutional level.

c. The most important variable contributing to the expressions of evaluations in Mandarin is facework, especially in connection with rapport-maintenance (RM). Conversely, in AE the highest predictor directly matches the meaning of modal verbs that are used while making an evaluation. This indicates comparatively less concern in AE to the effect that evaluations may have on the harmonious interactions with the addressee (e.g. whether s/he is going to agree with S'evaluation or not). 
d. Mandarin evaluations are characterised by extremely frequent clause-peripheral marking of intersubjectivity. This concurrence is significantly less prominent in the AE data.

All in all, with this study we focused on the important issue of inter-cultural variation of speech acts. In particular we showed that the very communicative act of evaluation varies significantly from Mandarin to AE. In the former, evaluations are normally marked as joint projects to be intersubjectively shared with the addressee. In $\mathrm{AE}$, the intersubjective dimension and the expectation of harmonious interaction are not as overtly marked categories when a speech act of evaluation needs to be realised.

\section{Bibliography}

Arundale, R. B. (2010). Constituting face in conversation: Face, face-work, and interactional achievement. Journal of Pragmatics, 42(8), 2078-2105.

Author 2013.

Author 2015.

Author 2016a.

Author 2016b.

Author 2017a.

Author 2017b.

Author 2017c.

Benwell, B., \& Stokoe, E. (2006). Discourse and identity. Edinburgh: Edinburgh University Press.

Bisang, W. (1996). "Areal typology and grammaticalization: processes of grammaticalization based on nouns and verbs in East and Mainland South East Asian languages". Studies in Language, 20(3), 519-597.

Breiman, L. (2001). Random forests. Machine learning, 45(1), 5-32.

Brown, P., \& Levinson, S. C. (1987). Politeness: Some universals in language usage (Vol. 4). Cambridge: Cambridge University Press.

Bybee, J., Perkins, R., \& Pagliuca, W. (1994). The evolution of grammar: Tense, aspect, and modality in the languages of the world. Chicago: University of Chicago Press.

Capone, A. (2005). Pragmemes (a study with reference to English and Italian). Journal of Pragmatics, 37(9), 1355-1371.

Chappell, Hilary and Alain Peyraube. (2016). Modality and Mood in Sinitic. In Jan Nuyts and Johan Van Der Auwera (Eds.)The Oxford Handbook of Modality and Mood, (pp. 296-329), Oxford: Oxford University Press.

Conrad, S., \& Biber, D. (2000). Adverbial marking of stance in speech and writing. Evaluation in text: Authorial stance and the construction of discourse, 56-73.

Culpeper, J. (2011). Impoliteness: Using language to cause offence. Cambridge: Cambridge University Press.

Dam-Jensen, H., \& Zethsen, K. K. (2007). Pragmatic patterns and the lexical system-A 
reassessment of evaluation in language. Journal of Pragmatics, 39(9), 1608-1623. Dehe, N., \& Wichmann, A. (2010). Sentence-initial I think (that) and I believe (that): Prosodic evidence for use as main clause, comment clause and discourse marker. Studies in Language, 34(1), 36-74.

Downing, A. (2001). "Surely you knew!": Surely as a marker of evidentiality and stance. Functions of language, 8(2), 251-282.

Englebretson, R. (2007). Stancetaking in discourse: Subjectivity, evaluation, interaction (Vol. 164): John Benjamins Publishing.

Faller, M. (2002). Semantics and pragmatics of evidentials in Cuzco Quechua. (PhD), Standford University.

Gao, G. (2009). 9. Face and self in Chinese communication. Equinox Publishing, 175-191.

Goffman, E. (1961). The Presentation of Self in Everyday Life. Penguin, London.

Goffman, E. (1967). On face-work. Interaction ritual, 5-45.

Halliday, M. A. K. (1994). Spoken and written modes of meaning. Media texts: Authors and readers, $51-73$.

Hansen, M.-B. M. (1998). The function of discourse particles: A study with special reference to spoken standard French (Vol. 53). Amsterdam: John Benjamins.

Haugh, Michael. (2009). Face and interaction. In: Bargiela-Chiappini, F., Haugh, M. (Eds.), Face, Communication and Social Interaction, (pp. 1-30), London: Equinox.

Haugh, M., \& Bargiela-Chiappini, F. (2010). Face in interaction. Journal of Pragmatics, 42(8), 2073-2077.

Hecht, Michael, Warren, Jennifer, Jung, Eura, Krieger, Janice. (2005). The communication theory of identity. In: Gudykunst, W. (Ed.), Theorizing about Intercultural Communication. Sage, Thousand Oaks, CA, pp. 257-278.

Heritage, J. (2001). Goffman, Garfinkel and conversation analysis. Discourse theory and practice: A reader, 47-56.

Heritage, J. (2012). Epistemics in action: Action formation and territories of knowledge. Research on Language \& Social Interaction, 45(1), 1-29.

Hothorn, T., Hornik, K., \& Zeileis, A. (2006). Unbiased recursive partitioning: A conditional inference framework. Journal of Computational and Graphical statistics, 15(3), 651-674.

Hunston, S., \& Thompson, G. (2000). Evaluation in text: Authorial stance and the construction of discourse: Authorial stance and the construction of discourse: Oxford University Press, UK.

Ide, S. (1989). Formal forms and discernment: Two neglected aspects of universals of linguistic politeness. Multilingua-journal of cross-cultural and interlanguage communication, 8(2-3), 223-248.

Ifantidou, E. (1994). Evidentials and relevance. (PhD), University of London, London. Kamio, A. (1997). Territory of Information. Amsterdam: John Benjamins.

Levshina, N. (2015). How to do linguistics with R: Data exploration and statistical analysis. Amsterdam: John Benjamins Publishing Company.

Lyons, J. (1977). Semantics (Vol. 2). Cambridge: Cambridge University Press.

Mao, L. R. (1994). Beyond politeness theory:'Face'revisited and renewed. Journal of Pragmatics, 21(5), 451-486.

Martin, J., \& White, P. (2005). Evaluative Key: Taking a Stance The Language of Evaluation (pp. 161-209): Springer.

Matsumoto, Y. (1988). Reexamination of the universality of face: Politeness phenomena in 
Japanese. Journal of Pragmatics, 12(4), 403-426.

Mey, J. L. (2001). Pragmatics: An Introduction. (2 ed. Vol. Oxford): Blackwell.

Narrog, H. (2005a). On defining modality again. Language Sciences, 27(2), 165-192.

Narrog, H. (2005b). Modality, mood, and change of modal meanings: A new perspective. Cognitive Linguistics, 16(4), 677-731.

Narrog, H. (2012). Modality, subjectivity, and semantic change: A cross-linguistic perspective.

Oxford: Oxford University Press.

Narrog, Heiko. (2016). “The expression of non-epistemic modal categories". En Jan Nuyts y Johan van der Auwera (Wds.), The Oxford handbook of modality and mood, (pp. 90-116), Oxford: Oxford University Press.

Nenadic, O., \& Greenacre, M. (2007). Correspondence analysis in R, with two-and threedimensional graphics: The ca package. Journal of statistical software, 20(3).

Nuyts, J. (2001). Epistemic modality, language, and conceptualization: a cognitive-pragmatic perspective. Amsterdam: John Benjamins.

Nuyts, J. (2012). Notions of (inter) subjectivity. English Text Construction, 5(1), 53-76. Palmer, F. R. (2001). Mood and modality. Cambridge: Cambridge University Press.

Palmer, F. R. (2001). Mood and modality. Cambridge: Cambridge University Press.

Papafragou, A. (2000). Modality: Issues in the semantics-pragmatics interface. Oxford: Elsevier.

Samra-Fredericks, D. (2010). Ethnomethodology and the moral accountability of interaction:

Navigating the conceptual terrain of 'face' and face-work. Journal of Pragmatics, 42(8), 2147-2157.

Searle, J. R. (1979). What is an intentional state? Mind, 88(349), 74-92.

Searle, J. R., \& Vanderveken, D. (1985). Foundations of illocutionary logic. Cambridge: Cambridge Universirty Press.

Simon-Vandenbergen, A.-M., \& Aijmer, K. (2007). The semantic field of modal certainty: A corpusbased study of English adverbs (Vol. 56): Walter de Gruyter.

Spencer-Oatey, H. (2005). (Im) politeness, face and perceptions of rapport: Unpackaging their bases and interrelationships. Journal of Politeness Research, 1(1), 95-119. Spencer-Oatey, H. (2008). Face,(im) politeness and rapport. Culturally speaking: Culture, communication and politeness theory, 2.

Spencer-Oatey, H., \& Ruhi, Ş. (2007). Identity, face and (im) politeness. Amsterdam: NorthHolland.

Sweetser, E. (1990). From etymology to pragmatics: Metaphorical and cultural aspects of semantic structure (Vol. 54). Cambridge: Cambridge University Press.

Tagliamonte, S. A., \& Baayen, R. H. (2012). Models, forests, and trees of York English: Was/were variation as a case study for statistical practice. Language variation and change, 24(2), 135-178.

Tottie, G., \& Hoffmann, S. (2006). Tag questions in British and American English. Journal of English Linguistics, 34(4), 283-311.

Traugott, E. C. (2010). Revisiting subjectification and intersubjectification. In K. Davidse \& L. Vandelanotte (Eds.), Subjectification, Intersubjectification and Grammaticalization (pp. 2970). Berlin: De Gruyter Mouton.

Traugott, E. C. (2016). On the rise of types of clause-final pragmatic markers in English. Journal of Historical Pragmatics, 17(1), 26-54.

Traugott, E. C., \& Dasher, R. B. (2002). Regularity in semantic change. Cambridge: Cambridge 
University Press.

Tree, J. E. F., \& Schrock, J. C. (1999). Discourse markers in spontaneous speech: Oh what a difference an oh makes. Journal of Memory and Language, 40(2), 280-295.

Tree, J. E. F., \& Schrock, J. C. (2002). Basic meanings of you know and I mean. Journal of Pragmatics, 34(6), 727-747.

Verhagen, A. (2005). Constructions of Intersubjectivity: Discourse, syntax and cognition. Oxford: Oxford University Press.

Waltereit, R. (2001). Modal particles and their functional equivalents: A speech-act-theoretic approach. Journal of Pragmatics, 33(9), 1391-1417.

Wu, R.-J. R. (2004). Stance in talk: A conversation analysis of Mandarin final particles (Vol. 117). Amsterdam: John Benjamins Publishing.

$\mathrm{Xu}$, J. N. (2007). Xiandai hanyu huayu qingtai yanjiu [A study on the discoursive modality of Mandarin Chinese]. Beijing: Dongfang. 